\title{
Desires and doubts on cultural sustainability: A study from Aotearoa New Zealand
}

\author{
Tahera Afrin ${ }^{1}$
}

\begin{abstract}
The original research project of this study was aimed to find out the components of culture and their impacts on ako (teaching-learning) within the early childhood teacher education programmes. Ethics Approval was obtained from AUT Ethics Committee. Under a socio-cultural theoretical framework, twelve lecturers from three Tertiary Education Organisations (TEOs) were interviewed. Three cohorts of student teachers from the same TEOs participated in focus groups. Using manual thematic coding, nine broad areas of cultural components were identified. These were bicultural contexts of Aotearoa, ethnicities and multi-culturalism, individual identities, cross-cultural interactions, comfort zone, female majority, socio-economic struggles, spirituality and technology. A recently developed framework for cultural sustainability (Soini and Dessein, 2016) were applied to these areas. Some of these components were identified as more inert and less dynamic, while the rest were recognised at the other end of the framework.

The data and the principle findings were contextual to Aotearoa New Zealand. However, the discussion considered the overall global trends in relation to education.
\end{abstract}

Keywords: Cultural diversity, cultural sustainability,

\section{Introduction:}

This article explains author's conceptualisation of sustainability of the cultural components of teacher education programmes. A review of literature identified several research projects related to diversity with regard to young children (Boutte, 2008; Warren, 2013). A very few of these were from the perspective of teacher education. This study was intended to contribute to this gap. A previously conducted research has identified nine areas of components from culture in the context of Aotearoa New Zealand early childhood teacher education programmes (Afrin, 2017). This MPhil study, granted ethical consent by the AUT Ethics Committee, used a socio-cultural research framework to know what are the commonly driven components of culture and if these have any impact on ako (means both teaching and learning in te reo Māori). Twelve lecturers from three Tertiary Education Organisations (TEOs) were interviewed. Three cohorts of student teachers from the same TEOs participated in focus groups. 

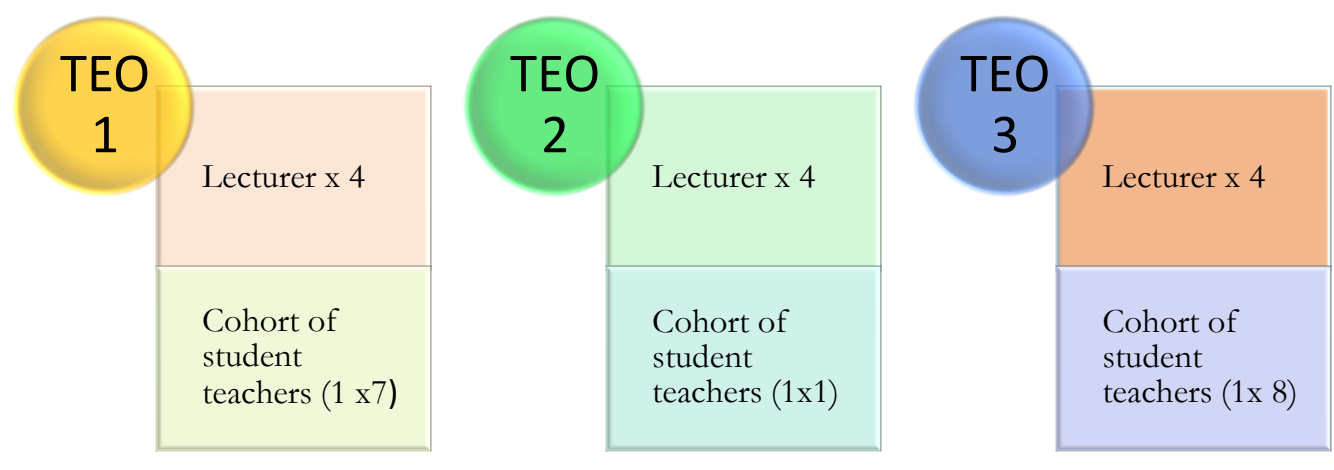

Figure 1: Distribution of participants

The participating TEOs are all located in Auckland, New Zealand. To ensure that the TEOs remain anonymous, three Bangla words were used as shown in the chart.

Table 1: Categories of three participating TEOs

\begin{tabular}{lll}
\hline TEO1 & TEO2 & TEO3 \\
\hline Janala & Durbeen & Ayna \\
\hline Polytechnic & University & Polytechnic \\
\hline
\end{tabular}

For this study I applied semi-structured interviews (Merriam \& Tisdell, 2015; Patton, 2015). The reason I extended this research is because I believe in a constantly changing world of teaching, it is important to explore more into the concept of culture in relation to sustainability. If we believe in the quote "We teach who we are" Palmer (1998, p. 1), curiosity on cultural components arises to see if and how our changing images impact on our teaching and future genrations.

\section{Cultural Components of Teacher Education in Aotearoa New Zealand:}

Using manual thematic coding, nine broad areas of cultural components were identified from the interviews and focus groups. These are bicultural contexts of Aotearoa, ethnicities and multi-culturalism, individual identities, cross-cultural interactions, comfort zone, female majority, socio-economic struggles, spirituality and technology. I explored these nine areas using the framework for cultural sustainability (Soini \& Dessein, 2016). The framework as stated in their study is as follows: 




Figure 2: Framework, for Cultural Sustainability, original cited from Soini \& Dessein, 2016

The graph includes the ideas of culture in, culture for and culture as (Soini et al., 2015). 'Culture in' means an effort is put into adding culture to the model of sustainable development to strengthen the pillars of sustainability beyond ecological and economic. 'Culture for' indicates an influential role of culture balancing the ecological and economic sustainability. 'Culture as' refers to ecological and economic sustainability intertwined within cultural sustainability. Less dynamic and less ecocentric gradients support 'culture in', more dynamic and more ecocentric supports 'culture as', and the other gradients promote 'culture for'.

With the above mentioned framework, the identified cultural components in the early childhood teacher education programme in Aotearoa New Zealand were revisited.

The first component is biculturalism. In Aotearoa New Zealand, it refers to the obligations of the founding document, the Treaty of Waitangi, between indigenous Māori and European settlers. All participants, lecturers and student teachers, appreciated biculturalism as a dominant cultural component of an early childhood teacher education classroom.

It (biculturalism) is very much there. And we know why. We know and respect the values of the Treaty. It is not surprising to us how all the papers we do have to refer to Te Tiriti o Waitangi (Janala Institute-Student teacher, FGD, 1/07/2015).

The dominance of biculturalism is, as noted by the participants, justified because of the influence of the curriculum document Te Whäriki (Ministry of Education, 2017a). Even though early childhood lecturers talked about incorporating Māori concepts in their teaching sessions, literature shows that there are still tokenistic uses of Māori tikanga in practice Jenkin, 2017; Ritchie, 2003; Williams et al., 2012). The teacher education programmes can be investigated to find ways to change this in ECE practice (Jenkin, 
2016). Biculturalism is more dynamic and less inert. As these are already part of a number of major documents related to teaching practice, biculturalism is more likely a sustainable component. Considering the political make-up of the country, it should be too.

Multiculturalism is the second component. Student teachers reported feeling empowered when they shared components from their culture. Sharing of these components were found helpful for perception building. Lecturers acknowledged these components as they believed these contributed to their emotional and professional growth. Intercultural competence, advocates steps such as ongoing curiosity and learning, attitudes of respect and openness, and critical thinking (Grey, 2013). Again, as multi-culturalism is a component where people's interest is involved, it is anthropocentric. It is probably more inert at this stage as there are negotiations that if multiculturalism is emphasised than biculturalism diminishes. Multiculturalism, from a practical perspectives were hardly ever mentioned in any major document until recently, with a focus on valuing community languages. However, with a rapidly changing world demographic, it is again a component that more likely to be moved to dynamic gradient, and sustainable.

The third component was individual identities. Many of the participants noted their professional identities as lecturers and student teachers while acknowledging identities in relation to birth place, family, and ancestors. These ideas reasonably match with the modern definition of identity. Identity in modern terms is no longer limited to social categories, but also refers to the sources that add self-respect or dignity for the individuals (Fearon, 1999), which may link to the Māori concept pepeha. Pepeha, which is practised in the field of early childhood, is a form of introduction that establishes relationships between individuals, their birthplace with geographical significance, and their ancestral heritage (Moore \& Moore, 2016). Pepeha, thus encourages ecological sustainability. Individual identities as professionals are more placed in the dynamic gradient as it is a recent development due to self-awareness. With the increase in selfaware involvement in social setting, it is more likely to sustain. Sustainable and encouraged individual identities will help, specially the minority to open up and talk about themselves, and their contribution to the society with pride and confidence.

The fourth component was cross-cultural interaction. Cross-cultural interactions were described infrequently in early childhood teacher education classrooms in spite of a large number of different ethnicities. There are patterns of students of similar ethnic backgrounds who share the same language, sitting together. However, this pattern is shown to be linked to individual comforts as opposed to racism or racist behaviour. This pattern matches the definition of race and ethnicity as described by Mason Durie (2005). He says race is biological variation and genetic determinism, but ethnicity has social and cultural connotations, lifestyle, and societal interaction. In this study, cross-cultural interaction is seen still as more inert and less dynamic. The pattern may need to change in order to achieve cultural sustainability. More access to open spaces may help this. Places and seating that allow movement were appreciated by the participants. These places were believed to have power in building connections between people.

While we were in the marae, I saw conversations happening between people that usually doesn't happen. In the classroom, you usually have a seat that you sit from the beginning of the first term till the end of the course. So, 
people sitting in front don't interact with people at the back. But in the marae, people were moving around (Hannah-Lecturer, Interview, 9/11/2015)

The fifth component was comfort zone. The formation of a comfort zone may come with conversations, actions, or physical settings.

It [sharing from student teachers] always comes after I discussed something from my life. For example, only when I share how my parents raised me up, do they talk about what they do to discipline their children, or how their parents raised them up. They feel that they can tell, they make jokes and that is when they also open up - only when they know that it is okay [to tell their stories in class]. (Sharon-Lecturer, Interview, 27/08/2015)

Thus, creating a comfort zone is a mandatory step of teaching-learning that empowers the student. When students feel the human side of the lecturers, they can be reassured of their own capabilities as they see lecturers as role models. Thus, again, I would say more of dynamic than of inert gradient. This also needs to be part of cultural sustainability where open communication between people break the barriers of power-relations.

The sixth component was female majority in early childhood teacher education programmes. Mostly, lecturers and student teachers in early childhood teacher education programmes are female. The participants of this study were aware of this and thought that male perspectives were being missed. Research has been done involving male early childhood educators with emphasis on having both male and female role models for children in early childhood education when they are developing their personality (Friedman, 2010, Farquhar, Cablk, Butler, \& Ballantyne, 2006)). This component, even though looking at very little increase in males in ECE teaching, is more likely to sustain. However, for achieving cultural sustainbilty, it is crucial that this pattern changes and equity in gender in shown in the profession.

The seventh component was spirituality. Spirituality in teaching is seen as knowing yourself and applying that knowledge in teaching so that it provides the right passion for the profession (Kung, 2011; Palmer, 1999). This passion is defined as call to teach when the teachers hear the inner call of the soul and put their heart into teaching. As described by one of the research participants in Kung's work (2011) that she did not choose the journey, but the journey of teaching chose her. The lecturer groups who participated in this research also referred to this aspect of spirituality as a motivational force for them to inspire their students. This is more inert gradient of cultural sustainability and probably would be a sustainable component, even with people who are atheists.

The eighth component was the economic factor. The importance of economy and its influence will always be prominent in any discussion of almost all topics. It can be noted here that even though sustainability is a concept traditionally focussed on natural environment, the concept of economical sustainability came almost hand by hand. The soci-cultural sustainability was emphasised only in Brundtland Report in 1987, and yet more than thirty years after, it is noted that cultural sustainability is merely researched or considered (Soini et al., 2015). A recent newspaper article in the New Zealand Herald sited a survey that shows one in six tertiary students are going without food (Collins, 2017). The article also includes information such as the students asking for donations of food and linen from the staff of the tertiary institute. The lecturer group who participated in this study also noted how the student teachers struggle financially to continue with their course especially when they go on practicum Two of the participating lecturers though questioned the poverty level of students and thought some of them 
used poverty as an excuse. They thought it is contradictory when the students cannot come to school or cannot print assignments because they did not have money, but are able to bear other expenses that can be seen as luxuries, such as smoking. There is a need for creating tertiary education where students can be supported.

The ninth component was technology. Technology is surely a dynamic gradient of sustainability that affects all areas of culture. In this study, technology as assessment practices and workplace requirements were commonly mentioned. Technology in ECE is already in the centres and the use of technology will keep on increasing (McMurtry \& Burkett, 2010). Students at every level have become increasingly tech-savvy (Lavin, Korte, \& Davies, 2011) and lecturers need to incorporate technology into practice to support the student teachers proficiency in digital competencies (McMurtry \& Burkett, 2010). One participant of this study acknowledged that not only the increasing use of technology in day to day life is important to notice, but also the moral challenges it places against the traditional view of the usual classroom disciplines can be an issue in the changing world. For example, use of phones, notebooks, and laptops in class is now more frequent and it opens up the question of if, when and how these tools are to be allowed or restricted in the classroom. Sharing of information in social media and privacy issues related to this was also discussed by this participant. Use of social media has become an important part of the identity of teenagers and adolescents of today's world where they negotiate complications, struggles and success and sense a high or poor level of self-esteem (Boyd, 2014). This is surely a component more situated in dynamic gradient.

In this study, a reflective model was developed by the researcher, which is included here. The purpose of this inclusion is to initiate thoughts that would support cultural sustainability. 
Does purposeful exchange of learning happen between the student-teachers and lecturers demonstrating a learning community?

Is the dominance of monocultural context diminished, and the practice of diversity eminent in delivery, assessment, and other areas of ako?
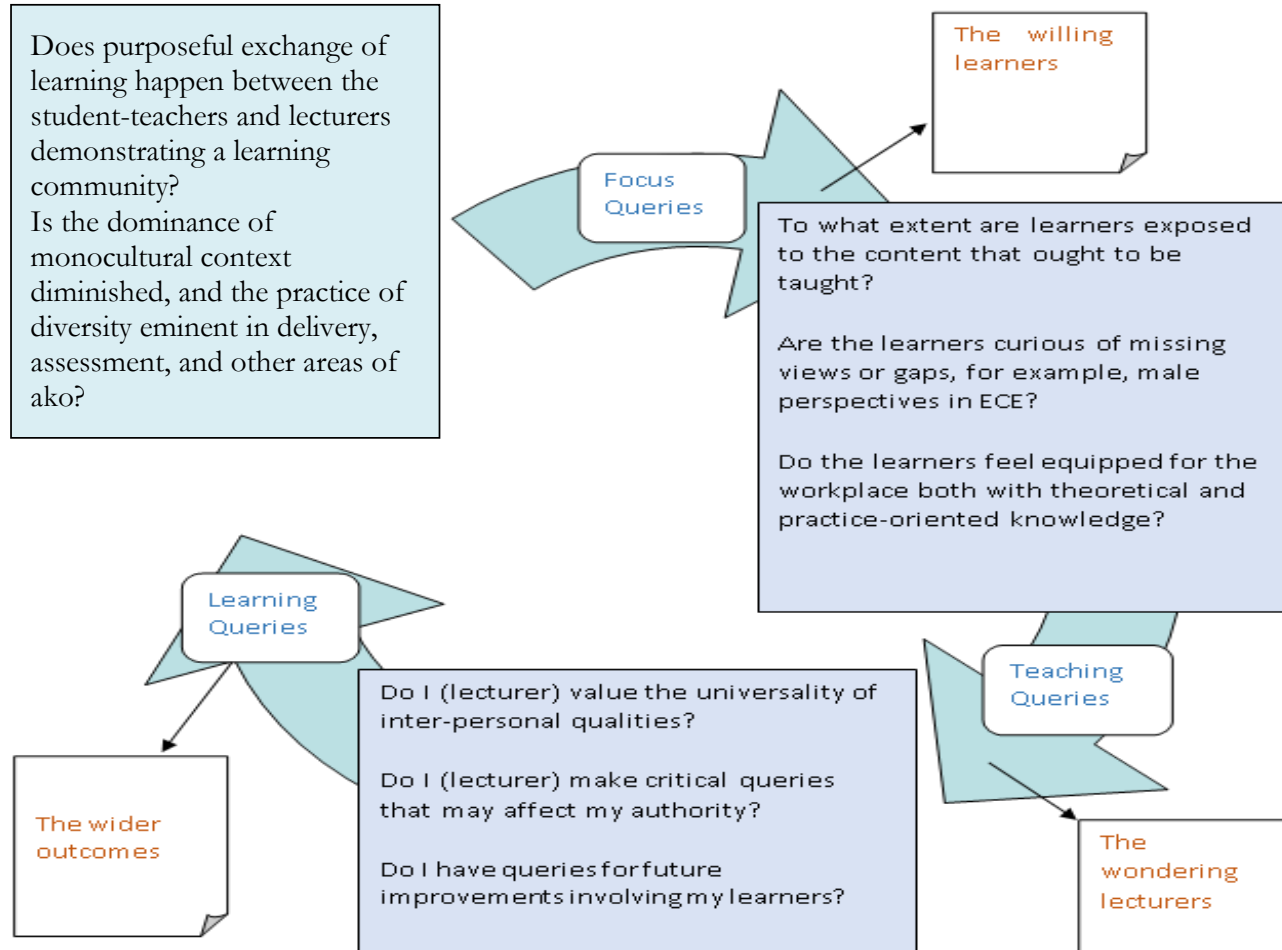

Do the learners feel equipped for the workplace both with theoretical and practice-oriented knowledge?

o I (lecturer) value the universality of inter-personal qualities?

Do I (lecturer) make critical queries that may affect my authority?

Do I have queries for future improvements involving my learners?

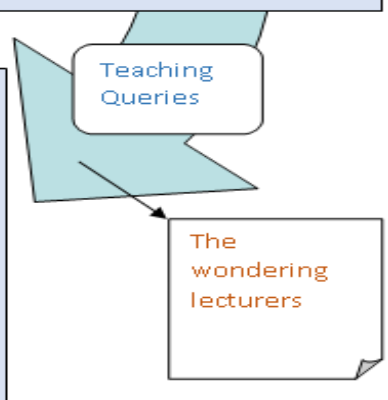

Figure 3: Queries on cultural components

\section{Conclusion:}

A study conducted in secondary schools in the US points at the divide between the diverse student groups and predominantly white teacher groups (Gay \& Howard, 2000), with a concern on lack of preparation of the teacher groups to deal with the student groups. Even in this study, the participating student teachers were diverse representing a number of ethnic groups, but the lecturers were limited to mostly European descendants. It reproduces an assumption that even though there are equal opportunities for education, it is limited in terms of academic employment. For cultural sustainability, it has to be changed. Things have had changed around the world over time, and it is important to keep the positive trends ongoing in education, and research. Cultural sustainability must be discussed first, and then be acted upon. 


\section{References:}

Afrin, T. (2017). Cultural components of early childhood teacher education programmes (Postgraduate Research Symposium). Auckland, New Zealand. Retrieved from http://www.aut.ac.nz/_data/assets/pdf_file/0007/577690/Tahera-Afrin-edited-forpublication.pdf

Boutte, G. S. (2008). Beyond the Illusion of Diversity: How Early Childhood Teachers Can Promote Social Justice. The Social Studies, 99(4), 165-173. https://doi.org/10.3200/TSSS.99.4.165-173

Farquhar, S.-E., Cablk, L., Butler, D., \& Ballantyne, R. (2006). Men at work:Sexism in early childhood education. Porirua: New Zealand Childforum Research Network.

Soini, K., Battaglini, E., Birkeland, I., Duxbury, N., Fairclough, G., Horlings, L., \& Dessein, J. (2015). Culture in, for and as Sustainable Development. Conclusions from the COST Action IS1007 Investigating Cultural Sustainability (1st ed.). (G. F. and L. H. Dessein, Katriina Soini, Ed.), Culture in, for and as Sustainable Development. University of Jyväskylä. https://doi.org/10.1017/CBO9781107415324.004

Soini, K., \& Dessein, J. (2016). Culture-Sustainability Relation: Towards a Conceptual Framework. Sustainability, 8(2), 167. https://doi.org/https://doi.org/10.3390/su8020167

Warren, A. (2013). "I wondered does this make me any less of a teacher ...?" Early childhood teachers in Aotearoa New Zealand claimed by and claiming authority within a dominant discourse. Journal of Early Childhood Research, 12(2), 185-194. https://doi.org/10.1177/1476718X12463914 